\title{
Influence of Exogenous Glucagon on Fetal Glucose Metabolism and Ketone Production
}

\author{
ANTHONY F. PHILIPPS, ${ }^{(37)}$ JOSEPH W. DUBIN, PAUL J. MATTY, AND JOHN R. RAYE \\ Department of Pediatrics, The University of Connecticut Health Center, School of Medicine, \\ Farmington, Connecticut, USA
}

\begin{abstract}
Summary
Acute glucagon injections were performed in chronically catheterized fetal lambs in late gestation to assess the fetal metabolic response to exogenous glucagon infusion. Glucagon dosages between $1 \mu \mathrm{g} / \mathrm{kg}$ and $1 \mathrm{mg} / \mathrm{kg}$ induced significant fetal hyperglycemia by 15-30 min postinjection, with peak glucose values $130-180 \%$ of control. Increasing responsivity to the same dose $/ \mathrm{kg}$ was noted to parallel increasing gestational age. In selected preparations in which umbilical venous catheters were implanted, glucagon injection caused an acute fall in the glucose/oxygen quotient and net umbilical glucose consumption. The fall in glucose consumption to $8 \%$ of control values occurred within $15 \mathrm{~min}$ of injection and suggests acute fetal glucose excretion, probably secondary to hepatic glycogenolysis. Glucagon injection in the neonatal lamb caused qualitatively similar increases in plasma glucose concentration but the quantitative responses were considerably greater. No change in fetal $\beta$-hydroxybutyrate $(\beta$-OHB) concentration was noted after injection; nor did the fetal uptake or excretion of this ketone change. The neonatal $\beta-O H B$ concentration was significantly different $(P<0.001)$ from fetal concentrations and did rise $14 \%$ above control after glucagon injection; thus, elevation of plasma glucagon in the fetus causes an acute hyperglycemia but, unlike the adult, does not induce a significant ketogenesis.
\end{abstract}

\section{Speculation}

The fetus in late gestation may respond to substrate deprivation by secretion of glucagon. If so, a modest but significant hyperglycemia would result, presumably the result of acute fetal glycogenolysis. The acute fetal metabolic adaptation to maternal starvation, however, if modified by glucagon, does not include utilization of ketones as alternate substrates.

Elevation of circulating plasma glucagon occurs in the adult in response to stimuli such as hypoglycemia, fasting or certain chemical secretogogues such as alanine or arginine (29). Hyperglucagonemia, due to either endogenously released glucagon or exogenous infusion, is associated with an immediate hyperglycemic response $(9,29)$. Although the glycogenolytic and gluconeogenic effects of glucagon upon hepatic glucose production are well known (29), it has also recently been suggested that glucagon secretion may play an important role in the normal regulation of hepatic glucose production in the resting state (19). In addition, ketogenic effects of glucagon stem from this hormone's ability to induce lipolysis and to stimulate hepatic fatty acid oxidation (5, 32 ); thus, glucagon secretion in the adult promotes the utilization of endogenous substrates for energy purposes, especially in times of stress.

Whether or not the mammalian fetus secretes glucagon in response to appropriate stimuli is controversial. Neither $\mathrm{Chez}$ and co-workers (7) nor Fiser et al. (11) were able to document changes in fetal glucagon concentration in primate or sheep fetuses, respectively, in response to a variety of stimuli. Other investigators
$(2,28)$ have shown that certain adult glucagon secretogogues such as arginine or epinephrine could produce a significant fetal hyperglucagonemia. Recent work (13) suggests that elevation in fetal glucagon concentration may accompany prolonged maternal fasting.

The physiologic function of fetal hyperglucagonemia is also open to question. A hyperglycemic response to pharmacologic injection has been suggested in in vivo preparations (6). In order to clarify the role of glucagon as a possible fetal metabolic regulatory hormone, we utilized the chronically catheterized fetal sheep as our model. Varying degrees of hyperglucagonemia were induced and alterations in fetal glucagon, insulin, glucose and ketone concentrations as well as umbilical glucose and ketone uptakes then noted.

\section{MATERIALS AND METHODS}

Experimental design. Eleven pregnant ewes between 118-149 days of gestation were studied (Table 1). Term gestation in the sheep is 147 days. All but two had singleton fetuses. Intravenous sodium pentobarbital and spinal anesthesia were administered to each animal preoperatively. Polyvinyl catheters were then placed in a fetal pedal artery and vein as well as the maternal femoral artery for purposes of sampling and infusion. In five of the fetal lambs umbilical venous catheters were also implanted. All catheters were then tunneled subcutaneously to a pouch on the mother's flank. Postoperative care and feeding were performed as previously described (22). Experiments were not performed until after a 4-day recovery period.

A total of 26 glucagon injections were performed in the experimental animals. When serial injections were performed, the dosages were administered in random order and at least $48 \mathrm{~h}$ separated exposure to exogenous glucagon. Crystalline beef/pork glucagon (33) dissolved in normal saline was injected by hand in a pedal vein over $1 \mathrm{~min}$. Dosages ranged from $0.001-1.0 \mathrm{mg} / \mathrm{kg}$ estimated fetal weight. Radioimmunoassayable insulin was measured in several lots of glucagon solution injected. Maximum insulin concentration determined was $120 \mu \mathrm{U} / \mathrm{ml}$. At the highest dose of glucagon utilized $(1.0 \mathrm{mg} / \mathrm{kg})$ this would cause a maximum elevation of $0.2 \mu \mathrm{U} / \mathrm{ml}$ in fetal plasma.

Fetal arterial blood for determination of plasma glucose concentration was withdrawn 2-3 times during the hour before injection and then at $15,30,60,90$, and $120 \mathrm{~min}$ postinjection. Due to limitations placed upon the amount of fetal blood withdrawn, however, only selected samples for determination of $\beta$-hydroxybutyrate ( 11 experiments), glucagon (10 experiments), and insulin (16 experiments) were available. Maternal arterial glucose, insulin, and glucagon concentrations were also assessed during control and experimental periods to detect any alterations in maternal homeostasis. In experiments done on the fetal lambs with umbilical venous catheters in place, fetal arterial and umbilical venous blood samples were withdrawn simultaneously and analyzed for whole blood oxygen contents, plasma glucose concentrations, and whole blood glucose and $\beta$-OHB concentrations. Arterial plasma 
Table 1. Characteristics of surgical preparations

\begin{tabular}{|c|c|c|c|c|}
\hline $\begin{array}{c}\text { Animal } \\
\text { no. }\end{array}$ & $\begin{array}{l}\text { Gestational age } \\
\text { at surgery (days) }\end{array}$ & $\begin{array}{l}\text { Gestational age } \\
\text { at injection } \\
\text { (days) }\end{array}$ & $\begin{array}{l}\text { Glucagon dose } \\
\text { (mg/kg) esti- } \\
\text { mated fetal } \\
\text { weight }\end{array}$ & $\begin{array}{c}\text { Single (S) } \\
\text { or Twin (T) }\end{array}$ \\
\hline \multirow[t]{3}{*}{1} & 130 & 141 & 1.0 & $\mathrm{~S}$ \\
\hline & & 143 & 1.0 & \\
\hline & & 147 & 1.0 & \\
\hline 2 & 124 & 143 & 1.0 & $S$ \\
\hline \multirow[t]{3}{*}{$3^{1}$} & 126 & 130 & 0.1 & $S$ \\
\hline & & 133 & 0.5 & \\
\hline & & 140 & 1.0 & \\
\hline \multirow[t]{3}{*}{$4^{1}$} & 123 & 127 & 0.1 & $S$ \\
\hline & & 130 & 0.5 & \\
\hline & & 133 & 1.0 & \\
\hline \multirow[t]{2}{*}{5} & 121 & 126 & 0.1 & $\mathrm{~S}$ \\
\hline & & 129 & 0.01 & \\
\hline \multirow[t]{2}{*}{$6^{1}$} & 129 & 133 & 0.1 & $S$ \\
\hline & & 136 & 0.01 & \\
\hline \multirow[t]{5}{*}{$7^{1}$} & 113 & 118 & 0.01 & $\mathbf{T}$ \\
\hline & & 120 & 0.1 & \\
\hline & & 133 & 0.001 & \\
\hline & & 139 & 0.1 & \\
\hline & & 141 & 0.01 & \\
\hline \multirow[t]{2}{*}{$8^{1}$} & 119 & 123 & 0.01 & $S$ \\
\hline & & 127 & 0.001 & \\
\hline \multirow[t]{3}{*}{9} & 117 & 122 & 0.001 & $\mathrm{~S}$ \\
\hline & & 125 & 0.001 & \\
\hline & & 130 & 0.1 & \\
\hline 10 & 116 & 131 & 0.001 & $\mathrm{~T}$ \\
\hline 11 & 115 & 149 & 0.1 & $\mathrm{~S}$ \\
\hline
\end{tabular}

${ }^{1}$ Denotes preparation with umbilical venous catheter.

insulin and glucagon concentrations were also assessed. Umbilical glucose/oxygen quotients were calculated according to the formula:

$$
\frac{\mathrm{G}}{\mathrm{O}_{2}}=\frac{\text { venoarterial glucose difference }(\mathrm{mM}) \times 6}{\text { venoarterial } \mathrm{O}_{2} \text { difference }(\mathrm{mM})}
$$

This dimensionless quantity mirrors fetal glucose consumption when oxygen consumption is stable (22). Due to limitations in blood drawing, umbilical blood flow was determined in selected experiments utilizing the antipyrine steady state diffusion technique (15). A separate fetal venous catheter was used for antipyrine infusion.

Net umbilical glucose uptake ( $\dot{Q}$ glu) was calculated from the Fick principle: $\dot{Q}$ glu $(\mathrm{mg} / \mathrm{kg} / \mathrm{min})=$ blood glucose venoarterial difference $(\mathrm{mg} / \mathrm{ml}) \times$ umbilical blood flow $(\mathrm{ml} / \mathrm{kg} / \mathrm{min})$. Fetal weight at time of injection was estimated by extrapolation using the known birth weight of each animal at delivery or autopsy and fetal lamb growth charts. Similar calculations were made for assessment of fetal oxygen and $\beta$-OHB consumption or production. Fetal hematocrit, $\mathrm{pH}, \mathrm{pCO}_{2}$ and $\mathrm{pO}_{2}$ (blood gases) and arterial blood pressure were determined during control and experimental periods to assure intactness of the preparations.

Six neonatal lambs less than 1 wk of age were also studied. Femoral venous and arterial catheters were placed under local anesthesia. After a 1-h recovery period serial blood samples were drawn as in the fetal experiments. Glucagon doses of 0.1 (four experiments), 0.01 (two experiments) and 0.001 (three experiments) $\mathrm{mg} / \mathrm{kg}$ were utilized. In the three lambs receiving more than one injection, the doses were randomized as in the fetal experiments and were separated by recovery periods of at least 48 h.

Biochemical studies. Whole blood glucose and plasma glucose were assayed utilizing glucose oxidase techniques (22). Whole blood oxygen content was measured with a Lex- $\mathrm{O}_{2}$-Con (Lexington Instrument Corp). $\beta$-OHB concentration was determined en- zymatically utilizing 3-hydroxybutyrate dehydrogenase (31). Antipyrine concentration was measured using the Technicon Autoanalyzer.

Glucagon radioimmunoassay was performed using a modification of Unger's technique (10) with the antibody $30 \mathrm{~K}$ and $\left[{ }^{125} \mathrm{I}\right]-$ glucagon. A double antibody separation method (16) was used with goat anti-rabbit gamma globulin. Insulin radioimmunoassay utilized a double antibody separation method (16) and ovine insulin standards (33). Blood for glucagon and insulin assays were treated immediately with a mixture of $10 \mathrm{U}$ heparin/500 K.I.U. Trasylol (34) per $1 \mathrm{ml}$ sample, centrifuged and the supernatant then stored at $-70^{\circ} \mathrm{C}$ until time of assay.

Statistical methods. Results are expressed as mean \pm S.E.M. Statistical significance was assessed ütilizing the paired and unpaired Student's $t$ tests. Differences in peak glucose concentration between different glucagon dosage groups were assessed using the one-way analysis of variance. Volumes of distribution (Vd) and glucagon half-life were calculated with aid of the "C-stripping" technique of curve fitting (24). The Vd was assumed to be stable over the range of glucagon doses utilized. Because the data best fit a two compartment pharmacokinetic model, the term half-life ( $\left.\mathrm{t}^{2} / 2\right)$ refers to the terminal, rather than initial $t \frac{1}{2}$.

\section{RESULTS}

Maternal control glucagon concentration was $295 \pm 118 \mathrm{pg} / \mathrm{ml}$ and did not change significantly after fetal glucagon injection. Similarly, no changes in maternal glucose or insulin concentrations were noted during the course of the experiments. Fetal control glucagon concentration was $159 \pm 24 \mathrm{pg} / \mathrm{ml}$, not significantly different from maternal control values. Neonatal lamb control glucagon concentrations $(208 \pm 21 \mathrm{pg} / \mathrm{ml})$ were above the mean fetal level but, although a trend was evident, the difference was not significant $(P<0.07)$. The mean fetal volume of distribution (Vd) and half life ( $\left.\mathrm{t}^{\mathrm{t}} / 2\right)$ for glucagon were similar over the range of dosages utilized $(0.001-1.0 \mathrm{mg} / \mathrm{kg})$ in complete kinetic studies. A representative example is shown in Figure 1. All decay curves were best described by a two compartment kinetic model. Mean fetal Vd and $t \frac{1}{2}$ for the pooled experiments were $505 \pm 107$ $\mathrm{ml} / \mathrm{kg}$ and $79 \pm 21 \mathrm{~min}$, respectively. In general, fetal glucagon injections of $0.1 \mathrm{mg} / \mathrm{kg}$ and above yielded initial fetal glucagon concentrations in excess of $0.5 \mu \mathrm{g} / \mathrm{ml}$, or approximately 5000 -fold above physiologic concentrations. Dosages of $1-10 \mu \mathrm{g} / \mathrm{kg}$ were associated with proportionately lower peak concentrations of glucagon (Fig. 2).

No changes were noted in fetal blood gases, hematocrit, or blood pressure during the glucagon injection experiments. Basal plasma glucose was $24.7 \pm 1.3 \mathrm{mg} / \mathrm{dl}$. Significant elevations in plasma glucose were noted at 15 and $30 \mathrm{~min}$ postinjection at all glucagon doses utilized $(P<0.05)$. Results were converted to \% change from baseline in order to minimize interanimal variability (Fig. 3). Peak elevation occurred by 30 min postinjection and ranged from $130-180 \%$ of basal plasma glucose concentration. Although the decline in glucose concentrations from 60-120 min differed between doses, the peak responses to doses of 0.01-1.0 $\mathrm{mg} / \mathrm{kg}$ glucagon were statistically similar. At a dosage of $1 \mu \mathrm{g} / \mathrm{kg}$, plasma glucose rose less than at higher doses $(P<0.05)$, reaching $29 \pm 13$ and $32 \pm 18 \%$ above baseline concentrations $(P<0.02)$ at 15 and $30 \mathrm{~min}$, respectively (Fig. 3). In selected experiments fetal glucose response to the same glucagon dose $/ \mathrm{kg}$ (adjusted for increasing fetal weight) was assessed at different gestational ages. A trend toward increasing responsivity to glucagon with advancing gestational age was evident. Sufficient data from injections at different gestational ages were available $(0.01-0.1 \mathrm{mg} / \mathrm{kg}$ glucagon) to contrast peak glucose response with gestational age (Fig. 4). Linear regression analysis delineated a significant relationship $(P<0.02)$ between advancing gestational age and degree of fetal hyperglycemia.

Figure 5 depicts the changes in the venoarterial difference of whole blood glucose and glucose $/ \mathrm{O}_{2}$ quotients after glucagon in the fetal lambs in which umbilical venous catheters were im- 


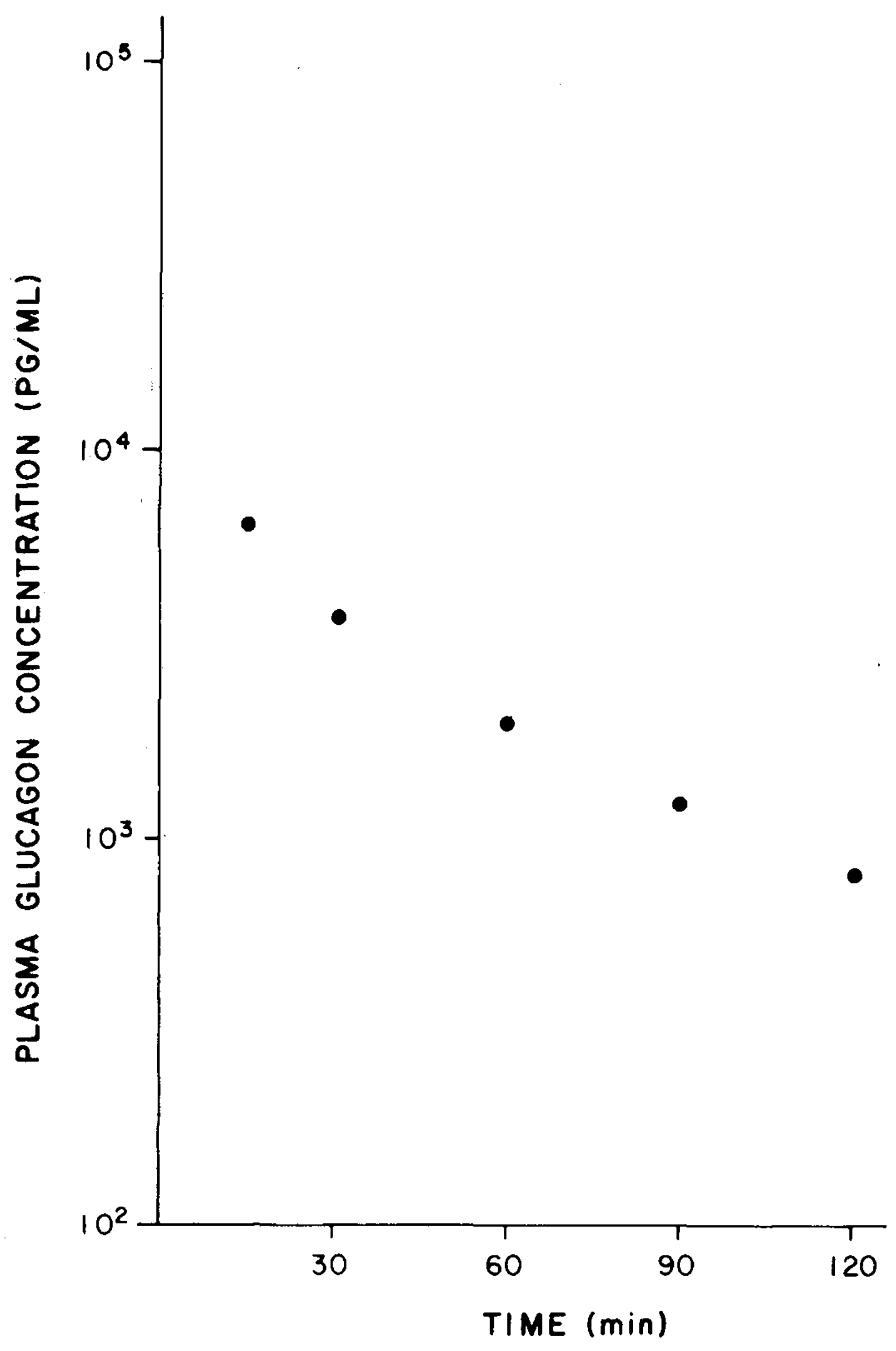

Fig. 1. Plasma arterial glucagon concentrations after injection of 0.01 $\mathrm{mg} / \mathrm{kg}$ glucagon in one fetal lamb (animal no. $8, \mathrm{Vd}=709 \mathrm{ml} / \mathrm{kg}, \mathrm{t}^{1 / 2}=$ $45.7 \mathrm{~min}$ ).

planted. Representative data from infusion dosages of $0.1-0.5 \mathrm{mg} /$ $\mathrm{kg}$ were pooled as no differences existed between the glucose responses seen at these dosages over the complete 2-h postinjection period. Significant elevation of arterial and umbilical whole blood venous glucose concentrations were demonstrated at 15,30 , and $60 \mathrm{~min}$ postinjection. Peak glucose concentration elevations for artery and vein occurred at $30 \mathrm{~min}$ postinjection, reaching 10.0 \pm 5.8 and $8.8 \pm 5.1 \mathrm{mg} / \mathrm{dl}$ above control levels, respectively. Basal $\mathrm{V}$-A glucose concentration difference was $2.88 \pm 0.70 \mathrm{mg} / \mathrm{dl}$. Postinjection values were below control at all points studied but the differences achieved statistical significance only at 30 and 90 min because of the relatively small numbers studied. At $30 \mathrm{~min}$ this difference was $41 \%$ of control. Small changes in arterial and umbilical venous whole blood $\mathrm{O}_{2}$ content occurred at 15,60 , and $120 \mathrm{~min}$ but no difference was greater than $15 \%$ from control values. Basal venoarterial oxygen content difference was $1.69 \pm$ $0.11 \mathrm{mM}$ and rose by $15-25 \%$ at 15,30 , and $90 \mathrm{~min}$. Despite this increase the $\mathrm{G} / \mathrm{O}_{2}$ quotient fell to $25 \%$ of control within $15-30$ min of injection $(P<0.01)$ and remained depressed until $120 \mathrm{~min}$.

Because a limited number of injections at doses of $0.01-1.0 \mathrm{mg} /$ $\mathrm{kg}$ were available in these animals and because no differences in peak glucose response were noted between these doses, the data from control and 15 and 30 min postinjection were pooled (Table 2). Again, statistically significant decrements in the venoarterial whole blood glucose difference were noted and were associated with an acute fall in the $\mathrm{G} / \mathrm{O}_{2}$ quotient. In five of these injections umbilical blood flow was measured, falling to $30 \%$ of control

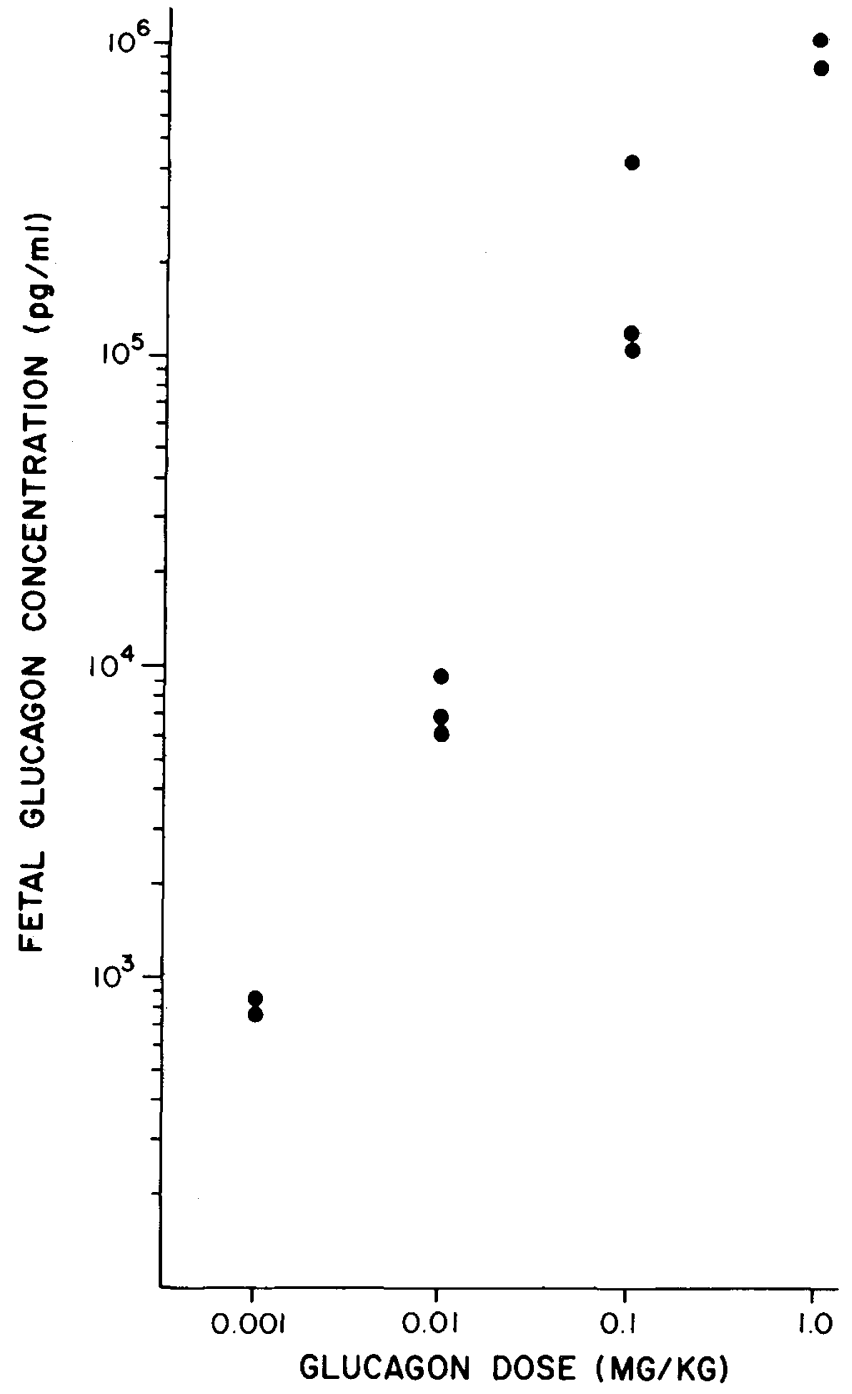

Fig. 2. Peak fetal glucagon concentration ( $15 \mathrm{~min})$ achieved after acute glucagon injection in five fetal lambs $(P<0.001)$.

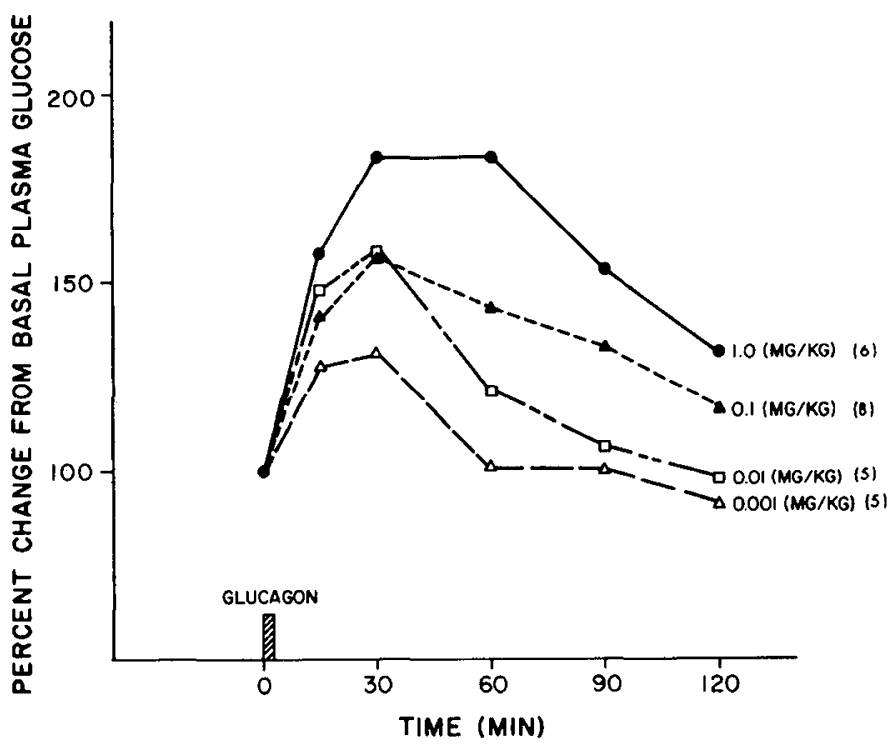

Fig. 3. Mean change in plasma glucose expressed as \% of basal in response to differing doses of glucagon in 11 fetal lambs. ()$=$ number of injections. 


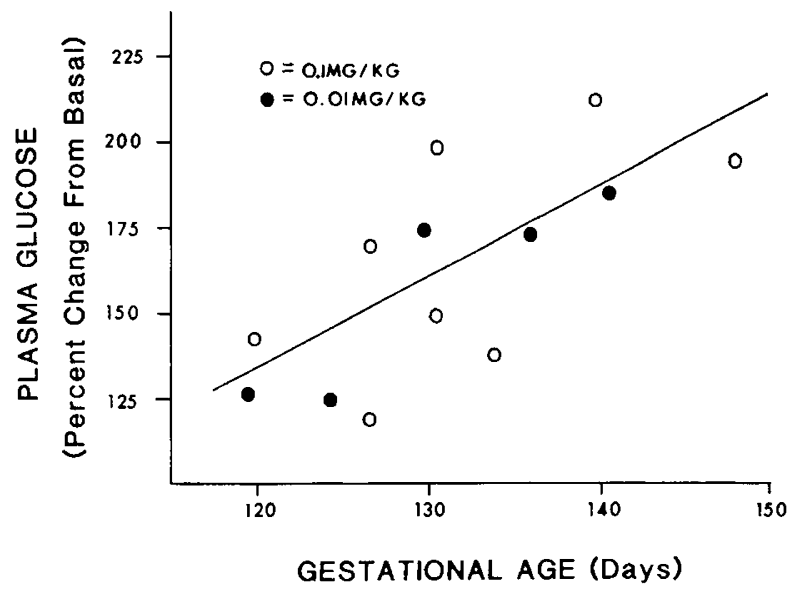

Fig. 4. Linear regression analysis of peak fetal hyperglycemic response $v s$ gestational age in eight lambs injected with 0.1 or $0.01 \mathrm{mg} / \mathrm{kg}$ glucagon. $(\mathrm{y}=2.31 \mathrm{x}-140.3, r=0.67, P<0.02)$.

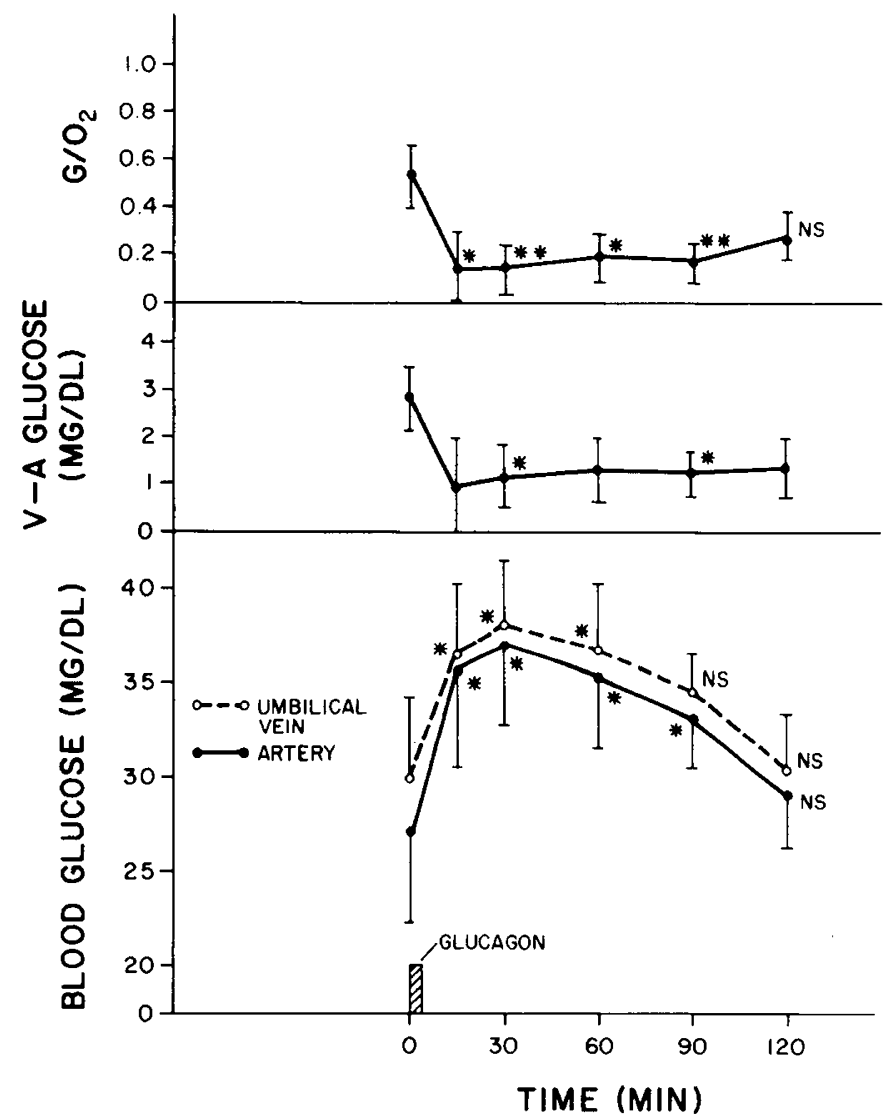

Fig. 5. Response of five fetal lambs to $0.1-0.5 \mathrm{mg} / \mathrm{kg}$ glucagon injection. Bars represent \pm 1 S.E. $\left({ }^{*}=P<0.01 ;{ }^{* *}=P<0.001 ; \mathrm{NS}=\right.$ not significant).

within $15 \mathrm{~min}$ of glucagon injection $\left(\triangle=5.10 \pm 1.53 \mathrm{mg} \cdot \mathrm{kg}^{-1}\right.$. $\min ^{-1}, P<0.03$ ). No significant changes were noted in fetal oxygen consumption or umbilical blood flow during these experiments.

Mean basal fetal plasma insulin concentration was $16.2 \pm 3.7$ $\mu \mathrm{U} / \mathrm{ml}$. As shown in Figure 6, elevations of fetal plasma insulin concentration were noted after glucagon injections at doses of 0.1 and $1.0 \mathrm{mg} / \mathrm{kg}$. Peak insulin concentrations ( $84 \pm 24$ and $50 \pm 25$ $\mu \mathrm{U} / \mathrm{ml}$ above baseline, respectively) were apparent by $60 \mathrm{~min}$ postinjection. Although a trend was noted, small elevations of insulin concentrations observed at glucagon doses of 0.001 and $0.01 \mathrm{mg} / \mathrm{kg}$ were not significantly above basal levels. No relation- ships were noted between the magnitudes of insulin responses in the fetal lambs and advancing gestational age, basal fetal glucose concentration or peak glucose concentration achieved post glucagon injection.

Neonatal lambs showed a brisk hyperglycemic response to the injection of all doses of glucagon utilized. Although the changes were qualitatively similar in fetal and neonatal lambs, the absolute magnitude of changes $(30 \mathrm{~min} \Delta$ plasma glucose $=61.3 \pm 20.8$ versus $11.7 \pm 1.6 \mathrm{mg} / \mathrm{dl}$ for neonate and fetus, respectively at 0.1 $\mathrm{mg} / \mathrm{kg}$ glucagon) were significantly different $(P<0.02)$. Similar results were apparent in the neonates when lower doses of glucagon $(1-10 \mu \mathrm{g} / \mathrm{kg})$ were utilized. At $1 \mu \mathrm{g} / \mathrm{kg}$ the peak glucose concentrations were $37.5 \pm 15.5$ versus $5.8 \pm 1.0 \mathrm{mg} / \mathrm{dl}$ above control for neonate and fetus, respectively $(P<0.02)$. Neonatal plasma insulin concentrations rose in response to the injection of $0.1 \mathrm{mg} / \mathrm{kg}$ glucagon. Although the responses were qualitatively similar to the fetal responses with a peak insulin concentration achieved by 30-60 min postinjection, the magnitude of response was greater (peak $\Delta$ insulin concentration $=90 \pm 36$ versus $45 \pm$ $26 \mu \mathrm{U} / \mathrm{ml}$ for neonate and fetus, respectively, $\mathrm{P}<0.05$ ). Only a limited number of injections were performed at the lower doses $(0.001-0.01 \mathrm{mg} / \mathrm{kg})$ in the neonatal lambs. Although the absolute increments above basal were in excess of those found in the fetal lambs, the differences between fetal and neonatal lambs were not statistically significant.

Basal fetal $\beta$-OHB concentration was $0.15 \pm 0.03 \mathrm{mM}$ and did not change at any dose of glucagon utilized.The data from glucagon injections of $0.01-1.0 \mathrm{mg} / \mathrm{kg}$ were, thus, pooled (Table 3 ). A negligible venoarterial $\beta-\mathrm{OHB}$ difference was detected in both control and experimental states. Neither this difference nor the

Table 2. Peak changes in glucose metabolism after injection of $0.01-1.0 \mathrm{mg} / \mathrm{kg}$ glucagon (five animals, 123-141 day gestation)

\begin{tabular}{lccc}
\hline & Control & $15 \mathrm{~min}$ & $30 \mathrm{~min}$ \\
\hline Plasma glucose $(\mathrm{mg} /$ & $27.4 \pm 2.8$ & $38.8 \pm 3.1$ & $40.0 \pm 2.3$ \\
dl) & $(9)^{1}$ & $P<0.001$ & $P<0.001$ \\
V-A glucose & $2.80 \pm 0.044$ & $0.50 \pm 0.57$ & $1.00 \pm 0.37$ \\
& $(9)$ & $P<0.01$ & $P<0.01$ \\
$\mathrm{G} / \mathrm{O}_{2}$ & $0.52 \pm 0.07$ & $0.08 \pm 0.09$ & $0.17 \pm 0.07$ \\
& $(9)$ & $P<0.001$ & $P<0.01$ \\
$\dot{\mathrm{Q}}$ glu & $7.22 \pm 1.50$ & $2.12 \pm 1.62$ & $3.02 \pm 1.11$ \\
$\mathrm{mg} \cdot \mathrm{kg}^{-1} \cdot \mathrm{min}^{-1}$ & $(5)$ & $P<0.03$ & $P<0.01$ \\
$\dot{\mathrm{Q} O} \mathrm{O}_{2}$ & $9.18 \pm 0.43$ & $9.90 \pm 0.74$ & $8.72 \pm 0.20$ \\
$\mathrm{ml} \cdot \mathrm{kg}^{-1} \cdot \mathrm{min}^{-1}$ & $(5)$ & N.S. & N.S. \\
\hline
\end{tabular}

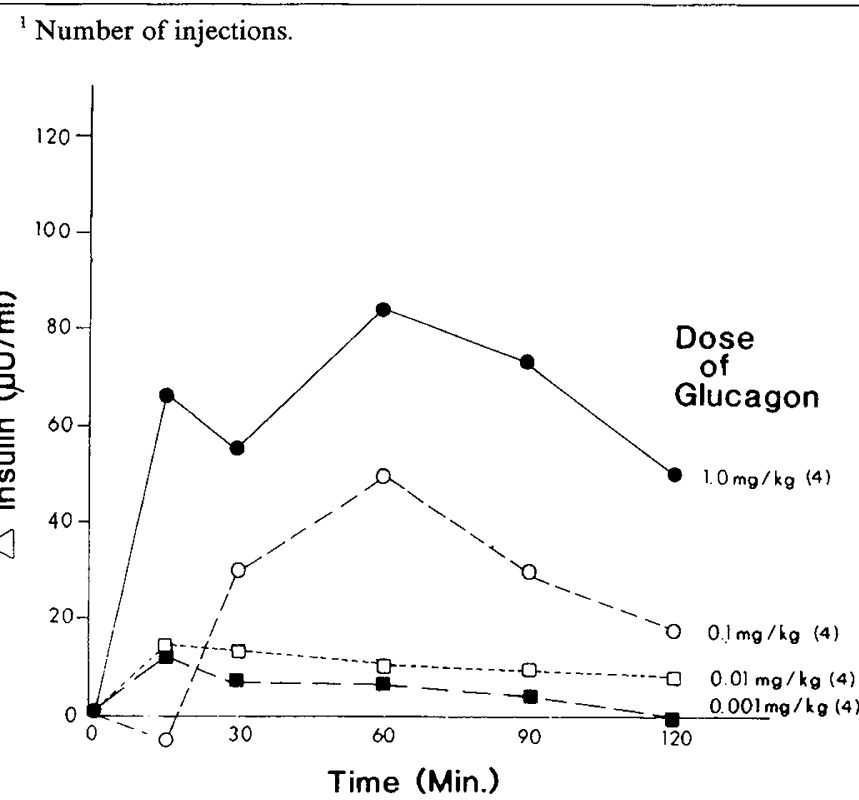

Fig. 6. Mean plasma arterial insulin increment in nine fetal lambs after varying doses of glucagon. 
Table 3. Change in $\beta$-hydroxybutyrate after injection of 0.01-1.0 $\mathrm{mg}$ glucagon in five fetal lambs and after $1.0 \mathrm{mg} / \mathrm{kg}$ in four neonatal lambs

\begin{tabular}{lccc}
\hline & $\begin{array}{c}\text { Fetal arterial hy- } \\
\text { droxybutyrate }(\mathrm{mM})\end{array}$ & $\begin{array}{c}\text { Venous-arterial hy- } \\
\text { droxybutyrate }(\mathrm{mM})\end{array}$ & $\begin{array}{c}\text { Neonatal arterial } \\
\text { hydroxybutyrate } \\
(\mathrm{mM})\end{array}$ \\
\hline Control & $0.15 \pm 0.03(11)^{1}$ & $0.0 \pm 0.03(7)$ & $0.42 \pm 0.05^{2}(4)$ \\
$30 \mathrm{~min}$ & $0.18 \pm 0.02$ & $-0.01 \pm 0.02$ & $0.48 \pm 0.06^{3}$ \\
$60 \mathrm{~min}$ & $0.16 \pm 0.02$ & $-0.03 \pm 0.02$ & $0.36 \pm 0.05$ \\
\hline
\end{tabular}

${ }^{1}()$, number of studies.

${ }^{2}$ Significantly different $(P<0.001)$ from fetal control.

${ }^{3}$ Significantly different $(P<0.05)$ from neonatal control.

umbilical $\beta$-OHB uptake was significantly different from 0 . Basal mean $\beta$-OHB concentration in the neonatal lambs studied, however, was elevated 3 -fold above the fetal concentration $(P<0.001)$. A small but significant elevation in $\beta$-OHB level was seen $30 \mathrm{~min}$ after injection of $0.1 \mathrm{mg} / \mathrm{kg}$ glucagon.

\section{DISCUSSION}

Although the glycogenolytic, gluconeogenic and lipolytic actions of pancreatic glucagon in the adult are well known $(5,9,19$, 29,32 ), the role that glucagon may play in the modulation of fetal metabolism is unclear. Glucagon is present in the fetal pancreas relatively early in gestation and, like insulin, does not readily cross the placenta (27). Although the fetal $\alpha$ cell response to adult stimuli such as alanine or hypoglycemia is minimal, responses to arginine (2) and epinephrine (28) have been noted. A surge of glucagon secretion occurs immediately after birth in several species including the sheep (14) and is associated with an acceleration of lipolysis and hepatic gluconeogenesis as well as a fall in hepatic glycogen content $(3,14,25)$, the latter suggesting stimulation of acute glycogenolysis. Both Girard, et al. (13) utilizing a fetal rat model, and Schreiner and co-workers (23), utilizing a chronically catheterized sheep preparation similar to our own, have documented modest but significant elevations of fetal glucagon concentration after prolonged maternal fasting and have suggested that this hormone may play a role in fetal metabolic homeostasis during times of stress. The effects of isolated hyperglucagonemia upon fetal metabolism have not been well characterized, however.

The chronically catheterized fetal sheep model has allowed us to study the pharmacokinetics and metabolic effects of acute fetal glucagon injection. The fetal glucagon half-life $\left(\mathrm{t}^{1 / 2}\right)$ of $79 \mathrm{~min}$ is longer than that found for insulin $(23 \mathrm{~min})$ in the fetal sheep (8), which may be related to accelerated insulin destruction due to the action of placental insulinase (18) as well as liver mediated catabolism. Glucagon extraction occurs predominantly in liver (17) and appeared constant over a wide range of doses in our study. This is consistent with the findings of Fisher and co-workers (12) in adult human subjects.

Injection of glucagon into the fetal lamb was associated with significant and rapid elevation of the fetal glucose concentration. Doses of $0.01-1.0 \mathrm{mg} / \mathrm{kg}$ of glucagon induced maximal responses by $30 \mathrm{~min}$ postinjection. The differences in prolongation of hyperglycemia (60-120 min) were dose dependent and may have been related to the absolute glucagon concentrations achieved. The concomitant findings of a depression of the glucose/oxygen quotient as well as a fall in the net umbilical glucose uptake speak for an acute increase in endogenous glucose production because increased fetal glucose excretion would decrease the umbilical venoarterial glucose difference.

Some controversy exists concerning the magnitude of the fetal capacity for hepatic gluconeogenesis $(3,4)$, particularly in the sheep, although it is clear that exogenous glucagon accelerates gluconeogenesis in in vitro systems (20). Girard and co-workers (13) have suggested that prolonged maternal fasting may prematurely induce a fetal capacity for hepatic gluconeogenesis but this has not yet been substantiated. Thus, the role of chronic hyper- glucagonemia in the induction of fetal gluconeogenesis remains to be elucidated.

In view of the rapidity of the hyperglycemic response to glucagon infusion, however, an acute hepatic and, perhaps renal, glycogenolytic response to glucagon is most likely in our experiments. The demonstration of increasing response to glucagon injection with advancing gestational age is also consistent with acute glucagon-stimulated glycogenolysis as liver glycogen content increases rapidly between 110 days and term in the fetal sheep (25). Enzymes necessary for glycogen synthesis as well as degradation are also present at this stage of gestation in the fetal sheep (3) as well as in other species (26). Increasing hepatic responsivity to glucagon, particularly with regard to hepatic adenyl cyclase activation (30) may also be important.

In the adult, hyperglucagonemia is associated with lipolysis, particularly in ruminants (5). In addition, glucagon stimulates hepatic ketogenesis and inhibits hepatic triglyceride synthesis (21, 32 ). During adaptation to fasting, lipidemia and ketonemia would serve to provide alternate energy sources, particularly to brain (1); however, in the sheep fetus exposed to prolonged maternal fasting (22) no elevation in free fatty acids was noted and despite small elevations of ketone bodies, no significant umbilical venoarterial difference was present, suggesting minimal fetal utilization of these substrates. Hyperglucagonemia in the fetal sheep was not associated with elevation of $\beta-\mathrm{OHB}$ concentration nor a significant increase in fetal $\beta-\mathrm{OHB}$ uptake or excretion. These findings are consistent with the view that the fetal adaptive response to maternal fasting, if modulated by glucagon, does not involve significant use of ketone as alternate substrate.

As in the adult, glucagon injection induced fetal insulin release that appeared unrelated to the hyperglycemia produced (9). At a dose of $1.0 \mathrm{mg} / \mathrm{kg}$ glucagon, the insulin response was maximal at 60 min postinjection and had not yet fallen to control values by $120 \mathrm{~min}$ postinjection. It is possible that endogenously produced insulin may have blunted the pronounced hyperglycemic response seen at this dosage. Because reactive hyperinsulinemia does depress the lipolytic and ketogenic actions of glucagon in adult sheep (5) it is also possible that endogenous fetal insulin release inhibited a rise in $\beta$-OHB concentration; however, the insulin increments in fetal experiments utilizing $0.1 \mathrm{mg} / \mathrm{kg}$ glucagon were relatively small, with peak values also obtained at $60 \mathrm{~min}$ postinjection. Because peak values obtained at the lowest doses $(0.001-0.01 \mathrm{mg} /$ $\mathrm{kg}$ ) were not statistically different from control insulin concentrations, it is unlikely that endogenously released insulin significantly depressed a hyperglycemic response or inhibited ketonemia at lower doses of glucagon. Neonatal $\beta$-OHB concentration was significantly above the fetal level, probably the result of both dietary and hormonal influences. It is interesting that a small but significant increase in $\beta$-OHB concentration was noted after glucagon, in spite of relatively larger insulin response in the neonatal lamb.

In summary, the role of acute hyperglucagonemia upon fetal metabolism has been investigated. Hyperglycemia, probably secondary to acute glycogenolysis, was noted at all glucagon doses including $1 \mu \mathrm{g} / \mathrm{kg}$, achieving glucagon concentrations similiar to those found in states of chronic maternal fasting (23). Although this response was quantitatively less than that of the neonate, it could conceivably be of benefit in conditions of severe substrate depletion, particularly because in this state insulin secretion is at a minimum (23). Ketonemia was not noted after glucagon injection and it is thus unlikely that endogenously elevated glucagon concentration would stimulate use of ketones as energy substrates acutely.

\section{REFERENCES AND NOTES}

1. Adam, P. A. J., Raiha, N., Raihala, E. L., and Kekomaki, M.: Oxidation of glucose and D-B-OH-butyrate by the early human fetus. Acta Paediatr. Scand., 64: 17 (1975).

2. Alexander, D. P., Assan, R., Britton, H. G., Fenton, E., and Redstone, D. Glucagon release in the sheep fetus I. Effect of hypo- and hyperglycemia and arginine. Biol. Neonate, 30: 1 (1976). 
3. Ballard, F. J. and Oliver, I. T.: Carbohydrate metabolism in liver from foetal and neonatal sheep. Biochem. J., 95: 191 (1965).

4. Bassett, J. M. and Jones, C. T.: Fetal glucose metabolism. In: R. W. Beard and P. W. Nathanielsz: Fetal Physiology and Medicine, pp. 158-172. (W.B. Saunders Company London 1976).

5. Brockman, R. P.: Effects of glucagon and insulin on lipolysis and ketogenesis in sheep. Can. J. Comp. Med., 40: 166 (1976).

6. Chez, R. A., Mintz, D. H., Horger, E. O., and Hutchinson, D. L.: Factors affecting the response to insulin in the normal subhuman pregnant primate. J. Clin Invest., 49: 1517 (1970).

7. Chez, R. A., Mintz, D. H., Epstein, M. F., Fleischman, A. R., Oakes, G. K., and Hutchinson, D. L.: Glucagon metabolism in nonhuman primate pregnancy. Am. J. Obstet. Gyn., 120: 690 (1974)

8. Colwill, J. R., Davis, J. R., Meschia, B., Makowski, E. L., Beck, P., and Battaglia, F. C.: Insulin-induced hypoglycemia in the ovine fetus in utero. Endocrinology, 87: 710 (1970).

9. Crockford, P. M., Porte, D., Jr., Wood, F. C., Jr., and Williams, R. H.: Effect of glucagon on serum insulin, plasma glucose and free fatty acids in man. Metabolism, 15: 114 (1966).

10. Faloona, G. R. and Unger, R. H.: Glucagon. In: B. M. Jaffee and H. R. Behrman Methods of Hormone Radioimmunoassay, pp. 317-330. (Academic Press, New York, New York, 1974).

11. Fiser, R. H., Jr., Erenberg, A., Sperling, M. A., Oh, W., and Fisher, D. A. Insulin-glucagon substrate interrelations in the fetal sheep. Pediatr. Res., 8: 951 (1974).

12. Fisher, M., Sherwin, R. S., Hendler, R., and Felig, P.: Kinetics of glucagon in man: effects of starvation. Proc. Natl. Acad. Sci., 73: 1735 (1976).

13. Girard, J. R., Ferre, P., Gilbert, M., Kervran, A., Assan, R., and Marliss, E. B. Fetal metabolic response to maternal fasting in the rat. Am. J. Physiol., 232: E456 (1977).

14. Grajwer, L. A., Sperling, M. A., Sack, J., and Fisher, D. A.: Possible mechanisms and significance of the neonatal surge in glucagon secretion: studies in newborn lambs. Pediatr. Res., 11: 833 (1977).

15. Meschia, G., Cotter, J. R., Makowski, E. L., and Barron, D. H.: Simultaneous measurement of uterine and umbilical blood flows and oxygen uptakes. Quart. J. Exp. Physiol., 52: 1 (1966).

16. Morgan, C. R. and Lazarow, A.: Immunoassay of insulin-two antibody system. Diatetes, 12: 115 (1963).

17. Pohl, S. L., Krans, H. M. J., Birnbaumer, L., and Rodbell, M.: Inactivation of glucagon by plasma membranes of rat liver. J. Biol. Chem., 247: 2295 (1972).

18. Posner, B. I.: Insulin metabolizing enzyme activities in human placental tissue. Diabetes, 22: 552 (1973).

19. Rizza, R. A. and Gerich, J. E.: Persistent effect of sustained hyperglucagonemia on glucose production in man. J. Clin. Endocr. Metab., 48: 352 (1979).

20. Savan, P. M. J., Jeacock, M. K., and Sheperd, D. A. L.: Hepatic gluconeogenesis in foetal and suckling lambs. Proc. Nutr. Soc., 35: 30A (1976).

Copyright (C) 1983 International Pediatric Research Foundation, Inc. $0031-3998 / 83 / 1701-0051 \$ 02.00 / 0$
21. Schade, D. S., Woodside, W., and Eaton, R. P.: The role of glucagon in the regulation of plasma lipids. Metabolism, 28: 874 (1979)

22. Schreiner, R. L., Burd, L. I., Jones, M. D., Jr., Lemons, J. A., Sheldon, R. E., Simmons, M. A., Battaglia, F. C., and Meschia, G.: Fetal metabolism in fasting sheep. In: L. Longo and D. Reneau: circulation of the Fetus and Newborn, pp. 197-222. (Garland Press, New York, New York 1978).

23. Schreiner, R. L., Lemons, J. A., Gresham, E. L., and Escobedo, M. B.: Fetal insulin and glucagon response to maternal fasting in the ewe. Pediatr. Res., 14 : 461 (1980).

24. Sedman, A. J. and Wagner, J. G.: C STRIP a fortran IV computer program for obtaining initial polyexponential parameter estimates. J. Pharm. Sci., 65: 1006 (1976).

25. Shelley, H. J.: Blood sugars and tissue carbohydrate in foetal and infant lambs and rhesus monkeys. J. Physiol., 153: 527 (1960).

26. Sparks, J. W., Lynch, A., Chez, R. A., and Glinsmann, W. H.: Glycogen regulation in isolated perfused near term monkey liver. Pediatr. Res., 10:51 (1976).

27. Sperling, M. A., Erenberg, A., Fiser, R. H., Oh, W., and Fisher, D. A.: Placental transfer of glucagon in sheep. Endocrinology, 93: 1435 (1973).

28. Sperling, M. A., Christensen, S. G., and Anand, R.: Adrenergic modulation of pancreatic hormone secretion in utero: Studies in fetal sheep. Pediatr. Res., 14: 203 (1980).

29. Unger, R. H.: Circulating pancreatic glucagon and extra pancreatic glucagonlike materials. In: D. F. Steiner and N. Freinkel: Handbook of Physiology, Section 7. Endocrinology Volume I. Endocrine Pancreas. pp. 529-534. (American Physiological Society, Washington, D. C. 1972).

30. Vinicor, F., Higdon, G., Clark, J. F., and Clark, C. M., Jr.: Development of glucagon sensitivity in neonatal rat liver. J. Clin. Invest., 58: 571 (1976).

31. Williamson, D. H. and Mellanby, J.: 3-D-B-Hydroxybutyrate. In: N. Y. Bergmeyer: Methods of Enzymatic Analysis. pp. 1836-1839. (Academic Press, New York, New York 1974).

32. Witters, L. A. and Trasko, C. S.: Regulation of hepatic free fatty acid metabolism by glucagon and insulin. Am. J. Physiol., 237: E23 (1979)

33. Eli Lilly Company, Indianapolis, Indiana.

34. FBA Pharmaceutical, New York, New York.

35. This research was supported by funds from National Institutes of Health grant AM 26067-01.

36. The authors wish to thank P. Kramer, Ph.D. and M. Testa, Ph.D. for advice regarding statistical analysis of the data and acknowledge the expert secretarial assistance of Mary Ann Peifer.

37. Requests for reprints should be addressed to: Anthony F. Philipps, M.D., University of Connecticut Health Center, Department of Pediatrics, Farmington, Connecticut 06032 (USA).

38. Received for publication April 10, 1981.

39. Accepted for publication April 28, 1982. 